\title{
Small-caliber endoscopes are more fragile than conventional endoscopes
}

\section{(ㄷ)(요 $\odot$}

\author{
Authors \\ Toshihiro Nishizawa ${ }^{1,2}$, Kosuke Sakitani ${ }^{1,3}$, Hidekazu Suzuki ${ }^{4}$, Tadahiro Yamakawa ${ }^{1}$, Yoshiyuki Takahashi ${ }^{1}$, Shuntaro \\ Yoshida $^{1,5}$, Yousuke Nakai ${ }^{5}$, Keisuke Hata ${ }^{1,6}$, Hirotoshi Ebinuma², Kazuhiko Koike ${ }^{5}$, Osamu Toyoshima1,5
}

Institutions

1 Gastroenterology, Toyoshima Endoscopy Clinic, Tokyo, Japan

2 Department of Gastroenterology and Hepatology, International University of Health and Welfare, Mita Hospital, Tokyo, Japan

3 Gastroenterology, Sakitani Endoscopy Clinic, ChibaTsudanuma, Japan

4 Department of Gastroenterology and Hepatology, Tokai University School of Medicine, Tokyo, Japan

5 Department of Gastroenterology, Graduate School of Medicine, The University of Tokyo, Tokyo, Japan

6 Department of Surgical Oncology, Graduate School of Medicine, The University of Tokyo, Tokyo, Japan

submitted 6.8.2019

accepted after revision $\quad 7.10 .2019$

Bibliography

DOI https://doi.org/10.1055/a-1036-6186 |

Endoscopy International Open 2019; 07: E1729-E1732

(c) Georg Thieme Verlag KG Stuttgart · New York

eISSN 2196-9736

Corresponding author

Osamu Toyoshima, MD, Gastroenterology, Toyoshima

Endoscopy Clinic, 6-17-5 Seijo, Setagaya-ku, Tokyo 157-

0066, Japan

Fax: +81-3-5429-9511

t@ichou.com

\section{ABSTRACT}

Background and study aims The repair costs of gastrointestinal endoscopes account for a significant proportion of the total budget of an endoscopy unit. This study evaluated the repair costs of small-caliber endoscopes and conventional endoscopes used in esophagogastroduodenoscopy (EGD).

Patients and methods A retrospective analysis of upper gastrointestinal endoscope damage and repair costs between April 2012 and May 2019 was performed at the Toyoshima Endoscopy Clinic. Conventional endoscopes (GIF-H260, GIF-HQ290, and GIF-H290Z) were used for transoral EGD while small-caliber endoscopes (GIF-XP260N and GIF-XP290N) were used for transnasal or transoral EGD. Results Three small-caliber endoscopes and five conventional endoscopes were used for 1,031 procedures and 31,192 procedures, respectively. The number of procedures/damage incidence for small-caliber endoscope and conventional endoscopes was 344 and 1950, respectively. Damage incidence for small-caliber endoscopes was significantly higher than for conventional endoscopes $(P=0.014)$. Repair costs/procedure were $\$ 5.95 \pm \$ 132$ for small-caliber endoscopes and $\$ 2.41 \pm \$ 115$ for conventional endoscopes. Repair costs/procedure for small-caliber endoscopes were more than twice those for conventional endoscopes.

Conclusions Small-caliber endoscopes are more fragile than conventional endoscopes.

\section{Introduction}

Esophagogastroduodenoscopy (EGD) is the routine method for investigating the upper digestive system [1-3]. Small-caliber gastrointestinal endoscopes have been developed and marketed and can be inserted transnasally [4,5]. Transnasal endoscopy is better tolerated, with high levels of patient comfort and acceptability and can be safely performed [6, 7]. However, there are several problems with small-caliber endoscopes. They have technical difficulties due to greater flexibility but limited optical capabilities. Video image resolution is inferior to con- ventional high-resolution endoscopes. Furthermore, image quality may be impaired when secretions or bubbles are present, as a result of poorer suction and lavage [8].

On the other hand, repair costs and maintenance of gastrointestinal endoscopy equipment represent an important share of the total budget of the endoscopy unit. Gastrointestinal endoscopes are damaged through routine wear and tear during procedures, as well as use of aggressive cleaning and disinfection processes [9]. However, repair costs of small-caliber versus conventional endoscopes have never been evaluated. This 
- Table 1 Repair costs for upper gastrointestinal endoscopes.

\begin{tabular}{|l|l|l|l|}
\hline & Small-caliber endoscope & Conventional endoscope \\
\hline Procedures performed & 1,031 & 31,192 \\
\hline Endoscopes & GIF-XP260N: 2 & GIF-H260: 2 \\
\hline (number) & GIF-XP290N: 1 & GIF-HQ290: 2 \\
\hline & & GIF-H290Z: 1 \\
\hline Duration of endoscope use & $86 \pm 61.5$ & $75.8 \pm 42.7$ \\
\hline (mean month \pm SD) & & \\
\hline Incidents of damage & 3 & 16 \\
\hline Procedures/damage incidence & 344 & 1950 \\
\hline Total repair costs (dollars) & 6137 & 75081 \\
\hline Repair costs/procedure & $5.95 \pm 132$ & $2.41 \pm 115$ \\
\hline (mean dollar \pm SD) & & \\
\hline SD, standard deviation. & & 0.014 \\
\hline
\end{tabular}

study evaluated repair costs of small-caliber and conventional endoscopes in EGD.

\section{Patients and methods}

A retrospective analysis of upper gastrointestinal endoscope damage and repair costs between April 2012 and May 2019 was performed at Toyoshima Endoscopy Clinic, an outpatient clinic specializingd in endoscopy. This study was approved by the Ethical Review Committee of the Hattori Clinic [10]. All clinical investigations were conducted according to the ethical guidelines of the Declaration of Helsinki.

At the time of analysis, the following upper gastrointestinal endoscopes were in use: Olympus GIF-H260, GIF-XP260N, GIFHQ290, GIF-H290Z, and GIF-XP290N. Data on repair costs were obtained from the archive of the invoices of gastrointestinal endoscope repairs and were then compared to the invoice copies from the service company (Olympus, Tokyo, Japan).

\section{Endoscopic examination}

EGD was used to evaluate patients with abdominal pain, gastrointestinal bleeding and iron-deficiency anemia, and those who had undergone screening for cancer, polyps, atrophic gastritis, and physical check-up. EGD was performed for diagnostic (observation and biopsies), not for therapeutic purposes, such as polypectomy. Conventional endoscopes (GIF-H260, GIFHQ290, and GIF-H290Z) were used for transoral EGD. Before starting, the pharynx of patients was topically anesthetized by gargling with $2 \%$ lidocaine hydrochloride viscous solution (Xylocaine Viscous 2\%, AstraZeneca Inc., Japan) [11]. Sedation with midazolam and/or pethidine was induced based on the patient's willingness [12,13]. Small-caliber endoscopes (GIFXP260N and GIF-XP290N) were used for transnasal EGD or transoral EGD. The nasal cavity was prepared by spraying three puffs of $0.05 \%$ naphazoline (Nippon Shinyaku Co., Ltd., Kyoto,
Japan), followed by $1 \mathrm{~mL}$ of $4 \%$ Xylocaine delivered as a fine mist using a mucosal atomization device. Furthermore, $3 \mathrm{~mL}$ of Xylocaine Viscous was injected into the nasal cavity. An endoscopic nurse assisted with every procedure. Use of small-caliber endoscopes was based on patient preference and better patient tolerability.

\section{Cleaning and disinfection of endoscopes}

High-level disinfection was achieved with an automated endoscope re-processor following manufacturer's instructions with strong acidic electrolyzed water (Kaigen pharma CO., LTD. Osaka, Japan). Both small-caliber and conventional endoscopes were sterilized using an automated endoscope re-processor. All endoscopes were stored in endoscope storage cabinets.

\section{Statistical analysis}

We compared incidence of damage and repair costs between small-caliber and conventional endoscopes with use of a Student's $t$-test or Welch's $t$-test or $X$-squared test. $P<0.05$ was considered statistically significant. Data were analyzed using the Stat Mate IV software (ATOMS, Tokyo, Japan).

\section{Results}

During the study period, 32,223 EGD procedures were performed. Characteristics of small-caliber and conventional endoscope groups are shown in $>$ Table 1 . Three small-caliber endoscopes and five conventional endoscopes were used for 1,031 procedures and 31,192 procedures, respectively. Duration of use for small-caliber and conventional endoscopes was $86 \pm 61.5$ months and $75.8 \pm 42.7$ months, respectively. The number of procedures/damage incidence for small-caliber endoscopes and conventional endoscopes was 344 and 1950, respectively. Damage incidence for small-caliber endoscopes was significantly higher than that for conventional endoscopes 
- Table 2 Types of endoscope damage.

\begin{tabular}{|c|c|c|c|c|}
\hline \multirow[t]{2}{*}{ Endoscope damage } & \multicolumn{2}{|c|}{ Small-caliber endoscope } & \multicolumn{2}{|c|}{ Conventional endoscope } \\
\hline & Occurrences & $\begin{array}{l}\text { Average repair } \\
\text { cost/damage } \\
\text { (dollars) }\end{array}$ & Occurrences & $\begin{array}{l}\text { Average repair } \\
\text { cost/damage } \\
\text { (dollars) }\end{array}$ \\
\hline Damage to the rubber coat on the distal bending section & 2 & 1356 & 5 & 2664 \\
\hline Damage to the scope connector & 0 & & 5 & 6492 \\
\hline Damage to the bending apparatus & 1 & 3425 & 2 & 3660 \\
\hline Damage to the external sheath & 0 & & 1 & 4773 \\
\hline Ocular damage & 0 & & 1 & 5407 \\
\hline Water channel damage & 0 & & 1 & 5708 \\
\hline Suction channel damage & 0 & & 1 & 6093 \\
\hline
\end{tabular}

$(P=0.014)$. Repair costs/procedure for the small-caliber and conventional endoscopes were $\$ 5.95 \pm \$ 132$ and $\$ 2.41 \pm \$$ 115 , respectively. Repair costs/procedure for the small-caliber endoscopes were more than twice those for the conventional endoscope $(P=0.396)$.

Types of endoscope damage are shown in $>$ Table 2 . The most frequent type of damage was to the rubber coat on the distal bending section.

\section{Discussion}

Small-caliber endoscopes had a higher frequency of repair than conventional endoscopes. Repair costs for small-caliber endoscopes could be twice that of conventional endoscopes. To the best of our knowledge, this is the first report about repair costs for small-caliber gastrointestinal endoscopes. Fragility and higher repair costs might have an impact on the management strategy of an endoscopy unit, such as the decision about purchase of small-caliber versus conventional endoscopes.

Repair costs/procedures for small-caliber and conventional endoscopes were $\$ 5.95 \pm \$ 132$ and $\$ 2.41 \pm \$ 115$, respectively. Repair costs for gastrointestinal endoscopes account for a significant proportion of the total budget of an endoscopy unit. The doctors and staff who handle endoscopes should recognize the expensive repair costs and avoid rough handling.

Damage to the rubber coat on the distal bending section was the most frequent type of damage. Extreme bending during endoscopic procedures puts the distal bending section under great mechanical stress, predisposing it to wear and tear [14]. Wear and tear damages occur not only during procedures but also during cleaning and maintenance. Because small-caliber endoscopes are thin, they break easily.

This study had some limitations. First, it was a retrospective review at a single institution. Second, patients were not randomized to either the thin endoscope group or conventional endoscope group; thus, there were background differences.

\section{Conclusion}

In conclusion, small-caliber endoscopes are more fragile than conventional endoscopes.

\section{Competing interests}

Dr. Suzukl has received scholarship funds from Daiichi-Sankyo Co. Ltd., EA Pharma Co. Ltd., Otsuka Pharmaceutical Co. Ltd, and Tsumura Co. Ltd. and service honoraria from Astellas Pharm Inc., Astra-Zeneca K.K., Daiichi-Sankyo Co. Ltd., EA Pharma Co. Ltd., Otsuka Pharmaceutical Co. Ltd, Mylan EPD., Takeda Pharmaceutical Co. Ltd, and Tsumura Co. Ltd.

\section{References}

[1] Sakitani K, Nishizawa T, Arita M et al. Early detection of gastric cancer after Helicobacter pylori eradication due to endoscopic surveillance. Helicobacter 2018; 23: e12503

[2] Toyoshima O, Nishizawa T, Arita M et al. Helicobacter pylori infection in subjects negative for high titer serum antibody. World J Gastroenterol 2018; 24: 1419-1428

[3] Nishizawa T, Suzuki H, Sakitani K et al. Family history is an independent risk factor for the progression of gastric atrophy among patients with Helicobacter pylori infection. United European Gastroenterol J 2017; 5: 32-36

[4] Osawa H, Yamamoto H, Miura Y et al. Diagnosis of depressed-type early gastric cancer using small-caliber endoscopy with flexible spectral imaging color enhancement. Dig Endosc 2012; 24: 231-236

[5] de Faria AA, Dias CAF, Dias Moetzsohn L et al. Feasibility of transnasal endoscopy in screening for esophageal and gastric varices in patients with chronic liver disease. Endosc Int Open 2017; 5: E646-E651

[6] Preiss C, Charton JP, Schumacher B et al. A randomized trial of unsedated transnasal small-caliber esophagogastroduodenoscopy (EGD) versus peroral small-caliber EGD versus conventional EGD. Endoscopy 2003; 35: 641-646

[7] Yagi ], Adachi K, Arima $\mathrm{N}$ et al. A prospective randomized comparative study on the safety and tolerability of transnasal esophagogastroduodenoscopy. Endoscopy 2005; 37: 1226-1231 
[8] Cho S, Arya N, Swan K et al. Unsedated transnasal endoscopy: a Canadian experience in daily practice. Can J Gastroenterol 2008; 22: 243-246

[9] Urayama S, Kozarek R, Raltz S. Evaluation of per-procedure equipment costs in an outpatient endoscopy center. Gastrointest Endosc 1996; 44: 129-132

[10] Nishizawa T, Sakitani K, Suzuki H et al. A combination of serum antiHelicobacter pylori antibody titer and Kyoto classification score could provide a more accurate diagnosis of $\mathrm{H}$ pylori. United European Gastroenterol J 2019; 7: 343-348
[11] Nishizawa T, Suzuki H, Arano T et al. Characteristics of gastric cancer detected within 1 year after successful eradication of Helicobacter pylori. J Clin Biochem Nutr 2016; 59: 226-230

[12] Cohen LB, Delegge MH, Aisenberg J et al. AGA Institute review of endoscopic sedation. Gastroenterology 2007; 133: 675-701

[13] Nishizawa T, Suzuki H, Arita M et al. Pethidine dose and female sex as risk factors for nausea after esophagogastroduodenoscopy. J Clin Biochem Nutr 2018; 63: 230-232

[14] Rozman A, Duh S, Petrinec-Primozic M et al. Flexible bronchoscope damage and repair costs in a bronchoscopy teaching unit. Respiration 2009; 77: 325-330 